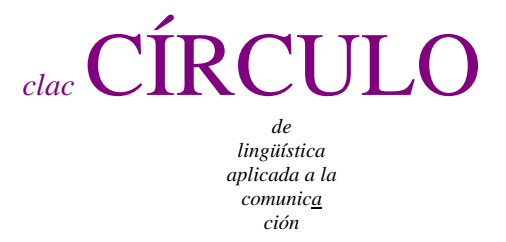

$46 / 2011$

\title{
LA LINGÜÍSTICA Y EL HISTORIADOR PERFECTO
}

\author{
Xavier Laborda Gil
}

xlaborda en ub edu

Universidad de Barcelona

\section{Resumen}

La búsqueda del historiador perfecto es la búsqueda de la historiografía que está renovando la historia de la lingüística. En primer lugar se esboza tres etapas de la historia de la lingüística, desde su fundación en 1902 por V. Thomsen, y sus representantes destacados, entre ellos Umberto Eco. A partir de la presentación por Eco de una ponencia sobre La búsqueda de la lengua perfecta en 1992 en el Congreso de Semiótica en La Coruña, y del modelo del laberinto o de la red multicursal del mismo Eco, se propone un decálogo del historiador de Babel, aplicable a la historiografía lingüística.

Palabras clave: historiografía, historia de la lingüística, Umberto Eco, lengua perfecta.

Laborda Gil, Xavier. 2011.

La Lingüística y el historiador perfecto.

Círculo de Lingüística Aplicada a la Comunicación 46, 51-90.

http://www.ucm.es/info/circulo/no46/laborda.pdf

http://dx.doi.org/10.5209/rev_CLAC.2011.v46.2 
Abstract: "Linguistics and the perfect historian”

The quest for the perfect historian is the search for historiography that is renewing the history of linguistics. First, the paper outlines three stages in the history of linguistics, since its founding in 1902 by V. Thomsen, and its prominent representatives, including Umberto Eco From Eco's presentation of a paper on The search for the perfect language in the 1992 Congress of Semiotics in La Coruña (Spain), and model of the maze or network multicursal Eco thereof, it is proposed a Decalogue of Babel story, which applies to linguistic historiography.

Keywords: historiography, history of linguistics, Umberto Eco, perfect language.

Índice

1. La búsqueda de la historiografía perfecta 53

2. Prestigio y polémica en torno a la historiografía 55

3. Eco, académico y celebridad 57

4. Babel y la lengua perfecta, en 199258

5. El programa historiográfico de la semiótica 61

6. Entre el canon y la propuesta universal 64

7. La historiografía, en el laberinto 68

8. El hallazgo de la isla perdida 74

9. El maestro Kircher 76

10. Decálogo del historiador de Babel 79

11. La historiografía y el lector 82

Referencias bibliográficas 85 
1. La búsqueda de la historiografía perfecta

La búsqueda del historiador perfecto es una forma de designar la excelencia de la historiografía como objetivo científico ${ }^{1}$. Plantea dilucidar qué historiador o, mejor aún, qué historiografía puede cumplir ese objetivo. Para ello corresponde considerar la trayectoria de la disciplina y de los historiadores que la representan en cada etapa. Probablemente el enunciado de esta búsqueda recuerde el título del ensayo de Umberto Eco, La búsqueda de la lengua perfecta (1993). Y esta asociación resulta apropiada, ya que constituye un capítulo brillante de la historiografía que motiva nuestro artículo.

La historia de la lingüística se construye con múltiples relatos. Es una obra colectiva en la que intervienen historiógrafos desde hace más de un siglo. Se inició en 1902, cuando Vilhelm Thomsen (Copenhague, 1842-1927) presentó en una festividad académica y publicó la primera obra que llevaba el título de Historia de la Lingüística. La fundación de la disciplina se debe a este prestigioso comparatista y rector de la Universidad de Copenhague, un episodio que comentamos más adelante. Su ensayo fue una referencia iluminadora durante sesenta años, hasta que la madurez de la lingüística estructural abrió nuevos horizontes a los historiadores.

Este cambio sucedió en 1964, con la publicación por Maurice Leroy de Las grandes corrientes de la Lingüística. ${ }^{2}$ La novedad de esta nueva etapa es que la obra de Leroy constituye la primera de una nutrida producción a la que han contribuido muchos autores. Otra novedad es la notable acogida que han obtenido los manuales de historia de la lingüística. La razón es el interés científico y también el prestigio social que consiguió la lingüística. El éxito de esta recepción se resume en la asunción de paradigma científico, con una gran influencia en todos los ámbitos del conocimiento. También sucede en la espectacular repercusión social de sus aportaciones: la semiótica aparece en artículos de prensa, la gramática estructural y generativa se enseña en la escuela y muchos de sus conceptos llegan al habla cotidiana.

\footnotetext{
${ }^{1}$ He leído con interés y satisfacción las propuestas de los revisores. Considero que han hecho un esfuerzo muy meritorio y espero haber aprovechado sus propuestas.

${ }^{2}$ Es más temprana la obra de Milka Ivic, de 1963, pero obtuvo difusión en su edición inglesa: Trends in Linguistics (Janua Linguarum, 1965).
} 
De entre la plétora de historiadores del estructuralismo destaca un nombre, Robert $\mathrm{H}$. Robins (1921-2000) por su Breve historia de la Lingüística (1967). Robins había escrito antes un ensayo preliminar, referido a la lingüística del mundo clásico (1951). A su obra general aportó el sólido conocimiento de las raíces greco-latinas y una perspectiva cultural de la historia muy sugestiva. La exposición de Robins recorría las épocas con equilibrado reparto de comentarios. A la simetría temporal del guión, que supone un rasgo inédito hasta su trabajo, añadía un riguroso análisis de los detalles. No en vano su nombre se ha inscrito como arquetipo de los historiadores de la lingüística. Junto a él figuran, con sobrado mérito, el mencionado Maurice Leroy, Milka Ivic o Carlo Tagliavini, con obras publicadas en los años sesenta. También hemos de incluir, entre otros, a Herman Parret, Eugenio Coseriu, Jesús Tuson, Roy Harris y Talbot Taylor, en los años setenta y ochenta.

¿Cuál de ellos podría representar el mejor modelo de la historia de la lingüística? Para hallar una respuesta hemos de considerar también autores posteriores y con rasgos diferenciados. En efecto, en los años noventa se produjo una nueva inflexión, que dio paso a otra etapa de la historiografía. En esta tercera etapa, contextual y hermenéutica, se ha puesto el énfasis en la metodología y en una perspectiva compleja del pensamiento lingüístico. Y así se cuenta con excelentes obras de Sylvain Auroux, Konrad Koerner, Pierre Swiggers, John Joseph o Vivien Law.

Cada etapa ha aportado logros y se ha adaptado a los cambios de la propia lingüística. Este proceso tiene el valor de ilustrar sobre la función inquisitiva de la historia y su naturaleza dinámica. El horizonte que se ha desvelado en cada etapa alimenta un corpus de obras y unos criterios de estudio. Una tras otro han aportado novedades sobre materiales conocidos o han sacado a la luz otros que parecían irrelevantes.

La enseñanza que se extrae es que ocuparse de la historia es estar siempre en camino. El trayecto no conduce a un destino definitivo, como quien recorre con la vista un árbol desde la base hasta la copa. El trayecto se asemeja más bien a la exploración de un laberinto que se ramifica y entrecruza. Ello es así porque los signos del pasado ofrecen interpretaciones según las preguntas que formule el historiador, en un diálogo de las voces del pasado con las inquietudes del presente. 


\section{Prestigio y polémica en torno a la historiografía}

La búsqueda del mejor historiador puede ser un cometido asequible, si nos guiamos por el criterio de la repercusión interna y también social. La respuesta bien puede ser un autor que no hemos mencionado en ninguna lista de las tres épocas, la fundacional, la estructural y la contextual. Se trata del lingüista que más ha influido en la lingüística moderna, Noam Chomsky. En 1966 Chomsky publicó una obra capital, Lingüística cartesiana, que despertó un interés inusitado no sólo entre los lingüistas sino también entre los humanistas. Y además provocó una intensa polémica entre los historiógrafos.

El ensayo sobre La lingüística cartesiana desarrolló la tesis de una lingüística racionalista en los siglos XVII y XVIII, que había surgido a la luz del pensamiento de Descartes. Chomsky relacionó la gramática generativa con la doctrina cartesiana y las gramáticas racionalistas, entre ellas la de Port-Royal (1660), una obra de Antonie Arnauld y Claude Lancelot, o la Minerva del Brocense (1587). Sin embargo, se criticó la tesis cartesiana por el descuido de los antecedentes de Port-Royal. Sin una perspectiva de la tradición gramatical, argüían los críticos, se corre el riesgo de distorsionar la historia (Aarsleff 1970). También se expresó objeciones a la existencia de una corriente cartesiana en gramática y a la originalidad de Port-Royal (Laborda 1978, c. 25).

La promoción que realizó Chomsky de la historia de la lingüística, con sólo un libro y un artículo a modo de resumen, supera toda comparación con cualquier otro autor ${ }^{3}$. Su influencia fue de tal magnitud que logró situar la Grammaire générale et raisonnée de Port-Royal, una obra desconocida para la historia de la lingüística, entre sus tópicos fundamentales. Desde entonces Port-Royal figura con un rango equiparable al Cratilo platónico y la gramática alejandrina de Dionisio el Tracio, las dos páginas más tratadas por los historiógrafos.

La incursión puntual de Chomshy en la historia es un hito que corresponde a la segunda etapa de la historiografía, la que va de 1960 a 1990. Como se ha dicho, precisamente de esta etapa cabe considerar como excelente representante a R. H. Robins. Resulta

\footnotetext{
${ }^{3}$ Sobre la tradición cartesiana, Chomsky también publicó el artículo "De quelques constantes de la théorie linguistique", en Diogène, 51, 1966, pp. 14-21.
} 
llamativo observar que, en contraste con el período estructural, las etapas precedente y posterior se inauguran con un acto festivo que tuvo una notable repercusión social. Se trata de las presentaciones académicas que hicieron V. Thomsen en 1902 y U. Eco en 1992.

Thomsen presentó la obra fundacional, Sprogvidenskabens historie; en kortfattet fremstilling (Historia de la Lingüística; una exposición concisa) en una ocasión especial. Fue el 8 de abril de 1902, con motivo de la fiesta anual de la universidad de Copenhague, de la que era rector el propio Thomsen. En su discurso expuso las razones de la importancia del conocimiento de la historia de la lingüística y presentó el que el constituía el primer volumen de una colección titulada "Introducción a la lingüística”. La festividad propició un escenario público excepcional, la ocasión solemne para un acto fundacional. Fue la presentación de la novedad de la historiografía lingüística (Laborda 2009).

Un salto temporal de noventa años nos sitúa en la tercera etapa de la historiografía. Y su presentación en sociedad se produjo en diciembre de 1992, en La Coruña, a cargo de Umberto Eco. Sucede que se celebró en la capital gallega el quinto congreso internacional de la Sociedad española de Semiótica. Y Eco presentó ante una audiencia multitudinaria una ponencia sobre sus investigaciones históricas relativas al sentido y la interpretación. Fue un acto con repercusión mediática y abierto al público sin restricciones. Constituyó el acontecimiento social del congreso, pero su trascendencia científica no se reveló entonces. Se ha revelado con la perspectiva que proporciona el tiempo y con las referencias que han aportado los nuevos historiadores: Auroux, Lepschy, Koerner, Asher, Swiggers, Joseph, Love, Taylor y Law. Hemos de puntualizar que no se trata de la identificación por estos autores del papel de Eco, sino de las contribuciones de todos ellos al paradigma de la historiografía contextual y hermenéutica. En el momento de la conferencia de Eco su carácter emblemático no era apreciable porque nacía sin un aviso explícito. 


\section{Eco, académico y celebridad}

La sede del V Congreso de la Asociación española de Semiótica fue el Palacio de Congresos de La Coruña. Umberto Eco fue el único académico que realizó su intervención en el auditorio Gaviota, que es la sala mayor del recinto. Tiene $1.500 \mathrm{~m}^{2}$ de planta y su escenario guarda proporción con el conjunto, pues mide 23 metros en el frontal, por 10 metros de fondo y de alto. Su aforo máximo es de 1498 plazas. La organización dispuso un escenario a la medida de una celebridad. La decisión fue osada pues, en buena parte, la expectación se debía a la figura del novelista de El nombre de la rosa (1980) y El péndulo de Foucault (1988). Pero el cometido de Eco era tratar de semiótica y de las lenguas en el Camino de Santiago.

Se acostumbra a presentar la polifacética figura de Umberto Eco (Alessandria, Piamonte, 1932) como filósofo, medievalista, lingüista, semiólogo y experto en comunicación de masas. ${ }^{4}$ Con su tesis doctoral, El problema estético en santo Tomás (1956), inició el desarrollo de lo que ha sido el eje de sus investigaciones, la historia del pensamiento sobre el signo. A partir de su Obra abierta (1962) se convirtió en el teórico de la semiótica de influencia internacional. Publicó Diario mínimo en 1963, una recopilación de artículos aparecidos a partir de 1959 en la revista cultural Il Verri. Estos breves ensayos tienen el atractivo de parodiar con paradojas y una erudición jocosa aspectos literarios, históricos, sociales o del espectáculo. Diario mínimo se publicó en castellano en 1964 y fue la primera traducción de Eco a cualquier lengua. Publicó también Apocalípticos e integrados (1965) y La estructura ausente (1968).

Según el propio Eco, hay una diferencia fundamental entre el ensayista y el novelista. Con humor distingue entre las dos categorías mediante una referencia a la audiencia.

\footnotetext{
${ }^{4}$ La relación de ensayos académicos y periodísticos de Eco destaca por el amplio rango de materias que abarca. Valga como ejemplo un título en apariencia menor y que, sin embargo, ha sido manual de investigadore: Cómo se hace una tesis (1977). Ha trabajado en televisión, en el mundo editorial, en las Universidades de Turín, Florencia, Milán y, a partir de 1975, en la de Bolonia como catedrático de Semiótica. Entre sus responsabilidades se cuenta la dirección de la revista VS-Quaderni di studi semiotici y de organismos como la International Association for Semiotic Studies o la Escuela Superior de Estudios Humanísticos de Bolonia. Y es miembro del Forum de la Unesco y de la Académie Universelle des Cultures de París.
} 
“Como ensayista vendía 10.000 ejemplares y como novelista, 1.000000” (Verdú 2010). Tras esta declaración de cuentas está la gran satisfacción que le produce ser un narrador y desarrollar una preceptiva poética personal. Esta faceta es congruente con la labor del historiador, que se expresa mediante un discurso narrativo, aunque normalmente no lo parezca. La consideración de la narrativa de Eco es relevante porque se relaciona con la idea de una historiografía como encrucijada de géneros. Eco publicó en 1980 su primera novela, El nombre de la rosa, que puso al autor al alcance del gran público. Y luego ha escrito cuatro novelas más: El péndulo de Foucault (1988), La isla del día de antes (1994), Baudolino (2000), La misteriosa llama de la reina Loana (2004) y El cementerio de Praga (2010). Cuando tuvo lugar el Congreso de La Coruña, Eco era una celebridad por sus dos primeras novelas. ${ }^{5}$

4. Babel y la lengua perfecta, en 1992

El V Congreso Internacional de la Sociedad Española de Semiótica se celebró entre los días 3 y 5 de diciembre de 1992, en el Palacio de Congresos de la Coruña. ${ }^{6}$. Según el programa, el titulo de la exposición versaba sobre las lenguas que se hablaban en el Camino de Santiago. El título sugería un escenario recorrido por peregrinos de una Babel medieval. La oportunidad del tema consistía en la reunión de la tierra de

\footnotetext{
${ }^{5}$ El nombre de la rosa es una combinación de crónica medieval y novela policíaca que narra las actividades detectivescas de Guillermo de Baskerville y su ayudante, Adso, para esclarecer los crímenes cometidos en una abadía benedictina en el silgo XIV. El péndulo de Foucault desarrolla una trama contemporánea sobre ciencias ocultas y sociedades secretas, que se desencadena a partir de un juego historiográfico. Unos editores inventan, por diversión, la historia de una conjura de templarios; pero la falsificación se convierte en una confusión dramática.

${ }^{6}$ Un indicio reciente de la capacidad de convocatoria de La Coruña fue el 40 aniversario de la Asociación Internacional de Estudios Semióticos, celebrado en el X Congreso Mundial de Semiótica (septiembre de 2009), con el propio José María Paz Gago como organizador, el que ya lo fuera en 1992.
} 
peregrinación -con el Xacobeo '93, a la puerta- y un especialista en cultura medieval ${ }^{7}$. Después de varios discursos de presentación, tomó la palabra el conferenciante. Y lo primero que expuso Eco, tras las cortesías de rigor, fue su desconocimiento sobre las lenguas que hablaban los peregrinos. Y comenzó a disertar sobre la "búsqueda de la lengua perfecta en la cultura europea”. Para ser coherente con el contenido, ese es el título que quedó reflejado en las actas (Paz, Fernández, Gómez 1994:79-94; Eco 1994b).

La búsqueda de la lengua perfecta es la crónica de una utopía apasionante que se ramifica en los tiempos como un laberinto inagotable. Eco indicó que se podía rastrear esa búsqueda a lo largo de casi dos mil años, desde la lengua prebabélica hasta los lenguajes formalizados artificiales. Tras escuchar los preámbulos sobre historiografía, una cuarta parte de los asistentes optó por retirarse. Los admiradores del novelista no hallaron un narrador de historias de intriga sino un erudito que describía ideas antiguas, lulianas, cabalísticas, dantescas y racionalistas, en una lengua que no era la lengua perfecta.

Eco planteó un problema de primer orden y se dispuso a confiar a la audiencia un razonamiento que podía resolver la cuestión. Su razonamiento se nutría de una fuente elocuente, la historia. Y fue la exposición de un conocimiento enciclopédico, magistral. Eran las indagaciones que había realizado en los últimos años sobre la búsqueda de una lengua perfecta en la cultura europea. Había expuesto esas ideas en el Collège de France y también lo haría en unas conferencias en la Universidad de Oxford, pero probablemente dio en La Coruña la primicia comprensiva del libro homónimo, La búsqueda de la lengua perfecta en la cultura europea, que publicaría Laterza en 1994. Es indiscutible que un magnífico resumen de la obra se halla en las actas del Congreso. ${ }^{8}$

\footnotetext{
7 Algunos ponentes ya habían tratado temas históricos, como los malentendidos sobre El Diario de Cristóbal Colón -por Jena Pierre Étienvre- o el discurso del tiempo, narrativa y peregrinación -por Carlos Reis.

${ }^{8}$ La ponencia se publicó también en la revista Cuadernos de Información y Comunicación (n. 4, 1999, p. 133-147) <http://revistas.ucm.es/inf/11357991/articulos/CIYC9899110133A.PDF>.
} 
La búsqueda de la lengua perfecta es "el sueño de una lengua capaz de hermanar a todos los hombres" (Eco 1994b:79). Es un viaje esquivo desde los pasajes bíblicos de la lengua adámica y la confusión de la torre de Babel hasta las lenguas a posteriori del barroco y del siglo XIX, como por ejemplo el esperanto. Aparece engarzada una nómina de modelos: el diálogo socrático del Cratilo, la teoría agustiniana sobre una lengua insólita que no está hecha de palabras sino de cosas, el proyecto de Dante en De Vulgari Eloquentiae de una lengua vulgar difusora de luz, la indagación en la estructura mágica del hebreo, los principios de los Modistas sobre una gramática universal o matriz de lenguas, la creación de códigos por los proyectistas del XVII, las tareas de desciframiento del jesuita Kircher, los enciclopedistas y su proyecto de una semántica universal...

La exploración histórica de Eco recoge, de un modo original y compresivo, reflexiones sobre el origen del lenguaje, la gramática universal y la relación entre palabras y cosas. El tema de la indagación es el don de lenguas o, dicho de otro modo, la matriz lingüística, la capacidad de inventar códigos y lenguas. Su finalidad es conseguir una herramienta para dos propósitos: el conocimiento certero, por una parte, y la comunicación eficaz y universal. Una de las enseñanzas de este viaje por la historia de las ideas sobre el lenguaje es la ubicuidad de los prejuicios etnolingüísticos. Con el concurso de gramáticos, muchos países europeos proclaman la excelencia de su lengua propia, que consideran heredera de la adámica. El nacionalismo lingüístico refuerza el mito y reivindica una superioridad que se confunde con razones políticas.

Fascina a Eco un factor dinámico en esta gran historia sobre la invención de la lengua perfecta. Se trata del cambio de motivaciones, que en algunos períodos se produce de siglo en siglo. La religión es una motivación determinante en la Edad Media, con un Raimundo Lulio llamado a crear un arte persuasivo que convenza a los representantes de las tres religiones. En el Renacimiento, se articulan religión y política, en la confrontación entre católicos y protestantes. En el siglo XVII, con la figura destacada de Kircher, se reúne ciencia y política, expresión de las ciencias y recurso para convertir a idólatras en la colonización del Nuevo Mundo. El siglo de las luces se vale de la lengua filosófica para una función ideológica y revolucionaria. A su vez, la revolución industrial acopla los ámbitos de la ciencia, la política y el comercio, con el esperanto 
como representante. $\mathrm{Y}$ en el s. XX se trabaja en la comprensión interespacial y otros mundos posibles.

Caben muchas críticas al sueño de una lengua capaz de hermanar a todos los hombres. Es una fantasía fundada en una leyenda bíblica: las creaciones son imperfectas y la aplicación social parece imposible. "Es justo reconocer a algunos trabajos pioneros el mérito de habernos aportado algo, aunque lo que nos hayan aportado no fuera lo que nos prometían", reconoce Eco (1994b: 80). Añade que, sin embargo, la historia ha sido provechosa para el conocimiento lingüístico. Y ha tenido efectos positivos en ámbitos como la lógica, la notación química, la clasificación zoológica o el lenguaje informático.

\section{El programa historiográfico de la semiótica}

Las obras de Eco suelen ir acompañadas de una relación de nombres o autores citados, porque lo necesitan y lo agradecen. El índice onomástico es signo de una edición pulcra y recurso fundamental para la consulta del discurso de Eco. Los índices de nombres son también un capítulo de la obra, en el sentido de que su revisión permite apreciar la variedad de entradas y la riqueza referencial que dispone. Junto a nombres consagrados cabe el hallazgo de rarezas. Y lo que es más significativo, de entre todos los nombres propios quedan señalados de modo inequívoco los autores que son el centro de su trabajo.

La búsqueda de la lengua perfecta es una narración -en el sentido de exposición de un historiador- que abarca la historia de la humanidad. Entre el origen mítico y la actualidad informática, Eco acude a múltiples autores y obras, pero sólo algunos de estos constituyen la base de su inquisición. Y son Raimundo Lulio y la Ars Magna, Dante Alighieri y De Vulgari Eloquentiae, John Wilkins y Essay towards a Real Character, la ingente producción de Athanasius Kircher o D’Alembert y la Encyclopédie. En el punto central de la historia, antes de la revolución conceptual de los enciclopedistas, se halla el proyectismo lingüístico del siglo XVII. 
Los grandes pensadores del s. XVII se ocupan de la lengua perfecta con cometidos diversos. Unos lo hacen para promoverla, como Bacon o Mersenne. Otros para criticar su oportunidad y fundamento, como Descartes o Newton, partidarios del cálculo y la notación matemática. También los hay que la estudian, como Kircher y Leibniz. Y finalmente hay un grupo de proyectistas que la desarrollan. Ese es el caso de Lodwick, Dalgarno, Bech, Becher y Wilkins. Como buscara siglos atrás el arte combinatorio de Lulio, los proyectistas intentan formular una lengua filosófica y de concordia. La invención de lenguas requiere de sus creadores una actividad metalingüística insólita, pues se trata de reflexionar sobre lo más abstracto y más primitivo de una lengua, la “forma locutionis, que constituye una gramática universal” (Eco 1994b: 83).

Los errores del proyectismo son clamorosos, pero enjuiciados con perspectiva no resultaron un fracaso. Un ejemplo llamativo de error es la teoría de que Dios pudo hablar en chino y que en la lengua oriental estaba cifrada la lengua madre. Con desacierto se reúne el deseo de la claridad filológica y la fascinación por los símbolos desconocidos del antiguo egipcio y del chino. Con estos esquemas el jesuita Athanasius Kircher realiza una labor ingente. Sus errores son, a juicio de Eco, una semilla de aciertos que germinaron mucho después. El historiador italiano señala la paradójica y fecunda vinculación entre el proyectismo y la investigación sobre el indoeuropeo, el otro “fantasma ideal”, la lengua matriz. “Este fantasma ya no es un punto del pasado al cual es necesario volver, sino la llave que permite explicar la historia y la evolución de las lenguas vivas” (Eco 1994b: 84). Y la conclusión que extrae del paso de la lengua perfecta al "fantasma ideal” del indoeuropeo es categórica: “tenemos así el nacimiento de la lingüística científica moderna y contemporánea”.

Llegados a este punto corresponde manifestar la novedad que supuso la conferencia de Umberto Eco. Fue una anécdota la sorpresa en la audiencia por la orientación que tomó su exposición. Más calado tuvo la elección de un tema no ya histórico sino historiográfico para lo que era un acontecimiento social. Estos dos aspectos fueron evidentes para los espectadores, pero no aquello que había de ser fundamental, por la sencilla razón de que faltaba perspectiva temporal para reconocer en aquella ponencia un acontecimiento determinante. Lo fundamental de la aportación de Eco fue la perspectiva inédita que abría a la historia de la lingüística. Es cierto que todos los autores que cita eran conocidos y que la historiografía precedente contaba con estudios 
relevantes. Ello resulta claro si reducimos la lista a Lulio, Dante, Kircher y Wilkins. Pero la relación que estableció entre estos autores es la trama original sobre la que organiza una historia extensa, de la Antigüedad a la actualidad, de las ideas sobre el lenguaje.

El esbozo de historia de la semiótica que Eco presentó en La Coruña fue una revelación, pero no supuso un giro brusco en su biografía intelectual. En las dos décadas precedentes formuló un manifiesto historiográfico y publicó estudios en obras de 1984 y 1990. Sin embargo, esa línea de investigación había quedado oscurecida por tareas más llamativas en semiótica teórica y de la cultura.

En Semiotics and the philosophy of language (1984a: 4) Eco recapituló sobre su formación como filósofo y su especialización en medievalística. Y declaró el interés que apreciaba -más allá de los autores de lingüística- en las fuentes filosóficas, para componer una historia de la semiótica. "Hasta el segundo congreso internacional de semiótica (Viena 1979) he insistido en la necesidad de proceder a una reconstrucción del pensamiento semiótico a partir de la época clásica”. Para aplicar su propuesta en esta obra de filosofía del lenguaje desarrolló un tratamiento histórico de los cinco conceptos básico en semiótica: signo, significado, metáfora, símbolo, código. Y concluyó diciendo que tal elección era una consecuencia “del proyecto de reconstrucción historiográfica” que caracterizaba su obra y que constituía una convicción personal. "Me he convencido cada vez más de que, para comprender mejor tantos problemas que aún nos preocupan, hay que proceder a la revisión de los contextos en que una determinada categoría ha aparecido por primera vez." 9 En

\footnotetext{
${ }^{9}$ Las citas proceden de la edición en catalán, Semiòtica i filosofia del llenguate (Barcelona, Laia, 1988, p. 5-6), que es más breve y con diferencias de redacción en la introducción respecto de la edición inglesa. Es significativo reseñar que entre los autores estudiados por Eco se hallan contemporáneos y vinculados en mayor o menor medida con la lingüística, como C. S. Peirce, Saussure, L. Hemlslev, J. Lacan, C. LéviStrauss, R. Jakobson, J. Derrida, P. Ricoeur, J. Searle. Pero también aparecen Platón, Aristóteles, los estoicos, Quintiliano, Sexto Empírico., Agustín de Hipona, Tomás de Aquino, entre una nómina de doscientos autores citados. En esta obra no aparecen aún los autores del s. XVII afectos al proyectismo lingüístico que constituirán el eje historiográfico de La lengua perfecta.
} 
consecuencia, el desarrollo de la teoría se asienta en la interpretación histórica de la génesis terminológica.

De la obra de 1984 hay que pasar a otra cercana al Congreso de La Coruña. Nos referimos a Los límites de la interpretación (1990), en la que Eco desarrolló las líneas de su programa historiográfico, si bien no se trata de una obra de carácter histórico ${ }^{10}$. Como es frecuente en muchos de sus títulos, una compilación de ensayos compuso una obra muy interesante sobre teoría e historia de la semiótica. Sorprendió al lector con un análisis del hermetismo, la alquimia y las lenguas mágicas, con especial referencia a dos de sus temas predilectos, los cabalistas y el lulismo ${ }^{11}$. Y también se ocupó del otro tema principal, los proyectistas barrocos, Johann Joachim Becher, Athanasius Kircher y John Wilkins. De entre éstos tomó a Wilkins por el estereotipo y lo distinguió de una manera singular. Eco inició su libro con una larga cita de Wilkins, que extrajo de una obra poco conocida, Mercury or the Secret and Swift Messenger (1641). La cita recogía un apólogo sobre un atribulado mensajero e ilustraba sobre la función de la escritura y la dificultad de realizar con fidelidad los encargos ${ }^{12}$.

6. Entre el canon y la propuesta universal

El gusto por el relato es uno de los rasgos que caracteriza la escritura ensayística de Eco. Se vale de este recurso para ilustrar aspectos teóricos, Por ejemplo, para exponer de una manera dialéctica una teoría sobre semántica universal, crea una situación teatral. Contrapone una mentalidad etnocéntrica a otra de inteligencia artificial, mediante un diálogo ficticio entre el Dr. Smith, especialista en Ciencias Cognitivas, y el ordenador

\footnotetext{
${ }^{10}$ Por la fecha de edición en castellano de Los límites de la interpretación (Lumen, 1992) y en catalán (Destino, 1991), su contenido era una novedad que sólo se reflejó en la "Presentación” de las actas del Congreso de La Coruña, de la mano de J. M. Paz (p.11-20).

${ }^{11}$ Dedicó a la historia de la baja Edad Media el capítulo 2, “Aspectos de la semiosis hermética” (p. 47114).

${ }^{12}$ La cita aparece en la página 9. También trata de la obra magna de Wilkins, An Essay towards a Real Character (1668), a propósito de un interesante diagrama de las preposiciones (p. 11, 77, 351).
} 
CSP. El diálogo aporta una curiosa argumentación sobre las condiciones de la interpretación, con la particularidad de que aparecen argumentos históricos. El fragmento que reproducimos tiene el interés añadido de mencionar la figura de Wilkins (Eco 1990: 351).

CSP — Un perro es un mamífero en cuanto se opone a un pez, de la misma manera en que Y se opone a O.Smith —Entiendo. En 1668 Wilkins, uno de nuestros sabios, intentó hacer lo mismo con “hacia”, “arriba”, “abajo”, “más allá”, etcétera. Dime al menos una cosa: ¿tú usas operadores como “si” o “entonces”? ¿Tratas la información según esquemas de razonamiento del tipo: si es verdadero que x es una rosa entonces es verdadero que $\mathrm{x}$ es una flor?CSP — Según mis instrucciones, cada vez que encuentro la palabra rosa extraigo una lista de interpretantes, entre los cuales, sin duda hay una flor.

Estos razonamientos aparecen en el extenso capítulo “Charles Sanders Personal: modelos de interpretación artificial” (Eco 1990: 335-356), donde Charles Sanders Personal es el ordenador CSP, de nombre parecido a C. S. Peirce. El diálogo ficticio, que Eco había publicado originalmente en 1986, discurre sobre la cognición y el signo lingüístico. Y ese es el ámbito exclusivo de la historiografía lingüística de Eco, que se desarrolla en las siguientes obras, en su mayor parte ya mencionadas:

\section{Semiotics and the philosophy of language (1984a)}

2. Los límites de la interpretación (1990)

3. "La búsqueda de la lengua perfecta en la cultura europea” (1992: Congreso de La Coruña, con actas de 1994)

\section{La búsqueda de la lengua perfecta en la cultura europea (1993)}

\section{Dall'albero al labirinto. Studi storici sul segno e l'interpretazione (2007)}

La novedad de la lista es la reciente aportación de 2007, Dall'albero al labirinto. Studi storici sul segno e l’interpretazione, En castellano, el título -sin edición castellanapuede ser Del árbol al laberinto. Estudios históricos sobre el signo y la interpretación. La continuidad de esta obra es clara porque amplía el modelo expuesto en 1984. Retoma los temas de Semiótica y filosofía del lenguaje y relanza el viejo manifiesto historiográfico. Como quien avanza girando en una espiral cada vez más amplia, Eco expone su programa de estudios históricos más preciso y amplio. Establece tres 
propuestas de estudio de la semiótica, que progresan de la lingüística a la literatura, pasando por la filosofía (2007: 12). Eco las enumera sin etiquetarlas, por lo que aquí identificamos como propuestas canónica, extensa y universal. El término "canónico" tiene un sentido descriptivo y se refiere al modelo que usualmente se considera propio de la lingüística.

Propuesta canónica,- Autores que han tratado del signo lingüístico, desde el Cratilo platónico hasta el lógico Peirce, pasando por Aristóteles y Agustín de Hipona, sin descuidar tratados de retórica y proyectos de lenguas artificiales como el de Wilkins. De estos elementos nucleares resulta una novedad la mención de la retórica, con la que expande el campo básico de la investigación. Eco ha tratado de la retórica de manera teorética -Le ragioni della retorica, 1987- y aplicada -Cinco escritos morales, 1996-, entre otras publicaciones.

Propuesta ampliada.- Se añade a la anterior el estudio de la historia de la filosofía que trata de manera implícita o embrionaria de la semiótica y no desarrollada. En este supuesto considera relevante la teoría de la percepción en Kant. La referencia es cabal pues Eco se ocupó de la cuestión en Kant y el ornitorrinco (1997), un libro cuyo autor considera capital en su obra. La amalgama de filosofía y semiótica aplicada a los mecanismos de la percepción constituye una continuación de la línea de estudio del Tratado de semiótica general (1975).

Propuesta universal.- Junto a los contenidos de las anteriores propuestas, Eco considera relevante el estudio en fuentes literarías de modelos implícitos sobre procesos comunicativos. Concretamente, señala como objetivo de estudio las estrategias simbólicas -en la obra del Pseudo Aeropagita, por ejemplo- y las estrategias hermenéuticas, como los bestiarios o las preceptivas poéticas.

La obra Dall'albero al labirinto se desenvuelve dentro de la propuesta canónica. Su particularidad es que constituye la culminación de los trabajos historiográficos de Eco. Conviene decir que es fiel a las raíces de sus primeras investigaciones, en los años ochenta. Y es fácil apreciar ciertas constantes porque retoma viejos capítulos ${ }^{13}$. A ello

\footnotetext{
${ }^{13}$ De la obra de 1984 retoma los capítulos 2, “Dictionary vs. Encyclopedia”, que aparece en 2007 como capítulo 1, con el título "Dall’albero al labirinto“; y el capítulo 3, "Metaphor”, que reaparece dividido en
} 
se añade un tratamiento renovado que permite ampliar tópicos y desvelar nuevos autores.

En Del árbol al laberinto compone un libro de historia con unos capítulos tan singulares como fundamentales. Relaciona las etimologías de Isidoro de Sevilla con los trabajos del ilustrado Joseph de Maistre (cap. 11). Vuelve al Ars luliana y examina la clasificación arbórea de la realidad, para compararla con la composición de la cábala y con su continuación renacentista en Pico della Mirándola (cap. 10). Relee De vulgari eloquentia y expone el papel de Dante, que emerge entre cabalistas y modistas (cap. 7). E introduce partes nuevas sobre la lengua perfecta, con especial atención a la figura de Wilkins y el siglo XVII. ${ }^{14}$

Como se ha indicado, su análisis encaja con la propuesta canónica, la que tiene como núcleo la Lingüística. Esta observación no ha de entenderse como la asimilación de la historiografía de Eco a la que es canónica en la Historia de la Lingüística. El modelo de Eco, incluso en su propuesta más circunspecta o limitada, resulta original para la historiografía usual. Cuánto más lo son las propuestas ampliada y universal.

dos capítulos, “Metafora como conoscenza: sfortuna di Aristotele nel Medioevo” (cap. 2) y “Dalla metáfora all’analogia entis” (cap 3).

14 Trata de la lengua perfecta en los capítulos 1 y 11. A propósito de los proyectistas y, en especial de Wilkins, Eco hace una declaración de su importancia, con el énfasis que aporta la referencia al título de la obra. "Il punto massimo della tensiones tra albero e labirinto si manifesta nell’Inghilterra del Sicento, intorno all'ambiente della Royal Society quando nascono diversi progetti di lingua filosófica a priori." (cap. 1.3.5, p 48). A continuación cita a Lodwick y A common Writing, Beck y The Universal Character, Dalgarno y Ars signorum, Wilkins y An Essay towards a Real Character.

Una nueva muestra de su consideración de la figura de Wilkins se halla en el discurso de su investidura como Doctor Honoris Causa por la Universidad de Sevilla (Eco 2009: 77-81). 


\section{La historiografía, en el laberinto}

El canon de Eco está construido con estudios de diversas épocas. Son artículos, conferencias o capítulos que ha redactado desde los años ochenta ${ }^{15}$. La obra más reciente, Dall'albero al labirinto, cuenta como una revisión y una ampliación de trabajos anteriores, que aparecen recopilados en el volumen de 2007. El título unifica los contenidos con un lema afortunado, una habilidad que ilumina las portadas de los ensayos de Eco. El mayor mérito de este título es que divulga, mediante la analogía del árbol y el laberinto, el dilema de la historiografía. Sin embargo, esta propuesta radical no es una novedad. Debemos acudir al Congreso de La Coruña para conocer la fecha de presentación del programa historiográfico de Eco. El texto de su exposición comenzaba así:

Mis indagaciones de los últimos años tienen que ver con la búsqueda de una lengua perfecta en la cultura europea. Similar a la "Isla Perdida" o a la "Tierra Ignota", a un Graal siempre prometido y nunca encontrado, la búsqueda de una lengua perfecta no ha dejado nunca de fascinar a los más grandes espíritus de la cultura europea: y sin embargo, mientras evoco aquí el sueño de una lengua única capaz de hermanar a todos los hombres. (Eco 1994b: 79)

De las especiales circunstancias en que intervino el aclamado académico se da fe en las actas. José Romera, presidente de la Asociación Española de Semiótica, manifestaba que “el poder de convocatoria de Umberto Eco culminó todas las previsiones”, por la gran afluencia de público que quería "ver y escuchar a una de las grandes figuras tanto del ámbito semiótico como del literario” (Paz 1994: 9). En efecto, fue un éxito de convocatoria a y el orador correspondió con entusiasmo y acierto ante un auditorio tan concurrido como desconcertado.

En realidad, no acaba en la esfera social la repercusión del acontecimiento, sino que afecta de una manera más duradera y profunda a la lingüística. Puede tenerse la

\footnotetext{
${ }^{15}$ Las dos partes fundamentales de la obra de 2007, publicadas como libro en Eco 1984, se remontan al año 1981, con "Dall'albero al labirinto" ( en A. Bonito Oliva, ed., Luoghi del silenzio imparziale, Milano, Feltrinelli) y al año 1983, con "L'antiporfirio" (en G. Vattimo e A Rovatti, eds., Il pensiero debole, .Milano, Feltrinelli, y posteriormente en Eco, Sugli specchi. Milano: Bompiani 1985).
} 
conferencia de Eco como la presentación en público de un programa historiográfico sorprendente e incomparable. No encaja en el modelo de la segunda etapa de la historia de la lingüística, la iniciada en los años sesenta y cuyo prototipo es el trabajo de Robins. Ello sucede a pesar de dos afinidades: tratar de autores conocidos, como Alighieri o Wilkins, y ocuparse de la teoría del signo como problema del conocimiento. Aparentemente los elementos y el propósito de Eco pertenecen al paradigma epistemológico, que es precisamente en el que destaca la segunda etapa de la lingüística (Laborda 2009). No obstante estas características, el programa de Eco es incomparable. Lo es porque se distingue por cinco rasgos nuevos: especialización, ampliación del corpus de autores y la tipología documental, énfasis metodológico y multimodalidad expositiva. Con estos rasgos acredita su pertenencia a una nueva etapa de la historiografía. Veamos el contenido de estos rasgos distintivos.

\section{a) Especialización}

La historiografía de la tercera etapa tiene un carácter especializado. Su objetivo no es abarcar toda la historia ni todas las contribuciones relevantes. Escoge un segmento temporal o una temática. Eco adopta la selección temática, a propósito de la confusión de las lenguas (confusio Inguarum) y con el objetivo de la búsqueda o la creación de la lengua perfecta.

b) Ampliación del corpus de autores

La especialización temática constituye un canon particular. Aplica unos criterios que ponen en valor períodos, autores y obras. Y el efecto más llamativo es la ampliación del rango de autores. Inscribe en la historia de la lingüística, por ejemplo, a Athanasius Kircher, Marino Mersenne, ambos implicados en el proyectismo del s. XVII. También de esa época, el cardenal y estadista Giulio Mazarino o, ya en nuestro tiempo, los escritores George Orwell y Jorge Luis Borges.

c) Ampliación de la tipología documental

El reconocimiento de autores inéditos en la historia de la lingüística va aparejado a la ampliación de la tipología de obras que estudia. Si recordamos las tres propuestas de 
Eco, en la segunda incluía las fuentes del ensayo filosófico y, en la tercera, la producción literaria. El rasgo de la amplia tipología documental manifiesta el dinamismo del programa historiográfico. Al mismo tiempo, plantea un escenario tan diverso y extenso como complejo.

d) Énfasis metodológico

Eco comparte con autores de la tercera etapa los rasgos expuestos. Y todos confluyen en la intención metodológica de la historiografía actual. En ello se diferencia de la tradición. La etapa fundacional de Thomsen constituyó el paradigma filológico, con la gramática como metalenguaje y el historicismo como modelo científico. En la segunda etapa, a partir de los años sesenta, se atribuyó al paradigma epistemológico la investigación historiográfica, con el metalenguaje de la semiótica y el referente de la gramática universal. Y en la siguiente etapa se ha puesto el énfasis en los criterios metodológicos, con el modelo de la hermenéutica o teoría de la interpretación histórica (Laborda 2002). Y Eco contribuye al paradigma metodológico o contextual de un modo singular, con un ameno y crítico discurso sobre su producción. Da razón de su método en obras de revisión como Apostillas a El nombre de la rosa (1983a), Seis paseos por los bosques narrativos(1994) o “Cómo escribo” (Eco 2002: 313-346).

e) Multimodalidad

El discurso de la historia es la narración no ficcional con una finalidad científica. No obstante esta estructura narrativa, en los ensayos historiográficos resultan más aparentes los patrones de la exposición y la argumentación. En la producción de Eco se produce la insólita reunión de trabajos argumentales y narrativos, como Obra abierta y El nombre de la rosa respectivamente. Por ello se distingue en él las facetas de semiótico y de novelista; y la crítica considera por separado su condición de académico y de literato.

Sin embargo Eco subvierte este orden previsible y desarrolla su actividad historiográfica mediante el ensayo y el relato de ficción. Como ejemplo de esta relación cabe señalar la íntima afinidad entre la investigación de La búsqueda de la lengua perfecta (1993) y la novela histórica La isla del día de antes (1994). La combinación de estructuras o 
patrones discursivos en la producción de Eco supone un hito. Es la entrada de la historiografía lingüística en la multimodalidad discursiva.

Los rasgos del programa de Eco conforman un escenario inédito. Al considerarlos por separado, observamos que cada rasgo es propio de la tercera etapa de la historiografía. Pero lo más llamativo del examen es que la articulación de éstos compone un paradigma interpretativo original. Como se ha apuntado, son los rasgos de la especialización temática i temporal, la ampliación del corpus de autores y la tipología documental, el énfasis metodológico y la multimodalidad de géneros. Y remiten a una historiografía de la complejidad y la investigación del laberinto de la historia pues, no en vano, el símbolo del laberinto es crucial en el pensamiento de Eco.

El laberinto es un modelo de la complejidad ${ }^{16}$. La primera publicación de Eco se debió a la exposición, en Milán el 1981, sobre "Lugares del silencio imparcial”. Esta convocatoria reunió obras de un elenco de artistas y promovió la reflexión de intelectuales sobre el laberinto contemporáneo (Eco 1981) ${ }^{17}$. Y otra aportación del semiótico apareció en 1984, con el prólogo a la sorprendente obra de Paolo Santarcangeli, El libro de los laberintos.

Las ideas de esta época son el troquel de su modelo de laberinto como red. Forma un conjunto ilimitado de canales, de múltiples posibilidades que se concretaran en unos recorridos. La tipología es importante, pero lo fundamental es su aplicación a las artes y la ciencia. En Apostillas a El nombre de la rosa (1983a) Eco aplica el concepto de laberinto a la preceptiva narrativa. "Todos los laberintos que conocía -y tenía a mi disposición el bello estudio de Santarcangeli- eran laberintos al aire libre. Los había bastante complicados y llenos de circunvalaciones. Pero yo necesitaba un laberinto cerrado” (p 38). Y Eco describe los tres tipos de laberinto (p. 66-7). El clásico es el

\footnotetext{
${ }^{16}$ Se inspira en la tradición arquitectónica, con una variedad de laberintos en jardines, en caseríos bereberes o en intrincados edificios. También proceden otros referentes del imaginario literario, impulsados en la modernidad por Jorge Luis Borges, Ítalo Calvino o StanislawLem; o la figuración plástica, con Salvador Dalí, Marcel Duchamp o Jackson Pollock (Bonito 1981).

${ }^{17}$ Una adaptación del escrito de 1981 aparecen en “El antiporfirio” (Eco 1983d), un capítulo publicado por Gianni Vattimo y Pier Aldo Rovatti en la edición de.1983 de El pensamiento débil (traducción castellana de Cátedra, 1988, p- 76-114).
} 
griego, el de Teseo, que conduce al centro, donde aguarda el Minotauro, y lleva luego a la salida. También está el laberinto manierista, “una especie de árbol, una estructura con raíces y muchos callejones sin salida” en el que "hay una sola salida, pero podemos equivocarnos”. Y en tercer lugar se halla el laberinto de la red o rizoma del callejero. Éste es el modelo que Eco propone para la historiografía. "No tiene centro, ni periferia, ni salida, porque es potencialmente infinito. Es espacio de la conjetura” (p 67).

Tanto en el ensayo como en la novela emergen el modelo y el tema del laberinto. En 1980 había publicado Eco la aclamada novela El nombre de la rosa. El centro de la trama gira en torno a la biblioteca, que es un laberinto bajo cubierto. Su creador lo define como un laberinto híbrido, pues es manierista en la forma y de red en la función. Esta condición se debe a que es estructurable pero nunca está definitivamente estructurado. Ese centro narrativo tiene una intención simbólica que trasciende la historia detectivesca, pues conduce a una dimensión estética y filosófica sobre la realidad. "Hasta el lector ingenuo barruntó que se encontraba ante una historia de laberintos, y no de laberintos espaciales” (1983a: 67). Para Eco, sea en la faceta de teórico como de novelista, no hay duda de que un relato que se ramifica en múltiples historias es un laberinto. Y por esa razón el relato tiene opciones de representar la complejidad de lo real.

Estas ideas sobre el laberinto, recurrentes en la obra de Eco, aglutinan la obra de compilación historiográfica de 2007, Dall'albero al labirinto. ${ }^{18}$ El nexo entre el modelo de red y la búsqueda de la lengua perfecta pertenece al siglo XVIII: el enciclopedismo de la ilustración. La crítica de d'Alembert en la Encyclopédie acaba con el proyecto de la gramática de las ideas, la de los eruditos como Wilkins (Espelt 2008: 26). El sueño de una lengua capaz de hermanar a todos los hombres se revela como imposible. La crítica enciclopedista es demoledora.

Eco confronta el modelo del diccionario con el de la enciclopedia. El diccionario es un árbol porfiriano, que clasifica los conceptos mediante dicotomías y referencias

\footnotetext{
${ }^{18}$ Sobre la metáfora del laberinto como modelo cultural cabe consultar a P. Santarcangeli (1967) y R. Espelt (2008, 2010), con abundantes referencias a Eco en Espelt (2008: 20. 25. 44 n.2, 51, 52, 57, 62, 76, 155-9).
} 
abstractas; es la síntesis de la predicación aristotélica y la clasificación de las cosas en géneros. El diccionario es el modelo de la unidad, que postula una competencia ideal en el usuario. Pero ha sido rebatido por el modelo de la enciclopedia, cuyos principios se exhiben con el símbolo del laberinto. El modelo de la enciclopedia postula una competencia histórica, socializada y en continuo movimiento. En vez de buscar una representación definitiva, cerrada y global, se aplica a determinados contextos. Esa localización del conocimiento aporta unos rasgos propios: importa la situación y, también, la perspectiva histórica. El saber es, como en el laberinto del tercer tipo, el acopio de un recorrido multicursal. ${ }^{19}$

La fuente de la teorización de Eco sobre el diccionario y la enciclopedia se halla en su Tratado de Semiótica General (1975: 184-5). Y esta contribución radical fue coetánea de una empresa intelectual que tuvo una gran repercusión. Entre 1970 y 1980 se publicó la reedición de la Encyclopédie de Diderot y d’Alembert (1751-1772). En el “Discurso preliminar”, d'Alembert estableció la vinculación entre laberinto y enciclopedia, una idea que ha sido determinante en el paradigma de Eco. Inmerso en este intento ambiente cultural, el semiótico participó en una obra que emula la proeza de los ilustrados. Es la edición de la Enciclopedia Einaudi (1977-1984), para la que colaboró en el noveno volumen, Laberinto-Memoria (1979), junto con R. Barthes o Jacques Le Goff, entre otros autores. $^{20}$

\footnotetext{
${ }^{19}$ La metáfora del laberinto como expresión del conocimiento como una red inabarcable y sorprendente tendría en la actualidad una versión en la red telemática. La dicotomía diccionario y enciclopedia de Eco podría equipararse a la de catedral y bazar de Eric S. Raymond (The Cathedral \& the Bazaar, 1997). Este ensayo a favor del software de código abierto parte de la comparación de dos perspectivas. El de la catedral pertenece a un mundo estructurado, jerárquico y estático, similar al del diccionario, que incita a contemplar su orden y a admirar su canon de belleza de autor. El del bazar o zoco representa ese otro mundo irregular en su disposición, azaroso, cambiante por la acción de los agentes, afecto a un lugar y unas circunstancias, afín a la enciclopedia y a la red del saber. Los símbolos del laberinto o de la red informática plantean una cuestión metodológica e interpretativa. Es la tensión de paradigmas, entre la unidad del árbol y la multiplicidad del laberinto.

${ }^{20}$ Eco participó en una experiencia editorial que puede concebirse como una fase de transición entre el laberinto de la enciclopedia y el de la red de Internet. Dirigió la primera enciclopedia multimedia sobre la cultura europea en soporte cd-rom, Encyclomedia; Guida multimediale alla storia della civilità europea (1995-1999).
} 
8. El hallazgo de la isla perdida

Borges es una referencia fundamental para Eco. En la narrativa de Borges el laberinto ocupa un lugar de preferencia. Y una modalidad de laberinto es la biblioteca de Babel, esa institución imaginaria en la que se almacenan todos los libros posibles, los creados y los que podrían crearse. Por otra parte, Borges es, al igual que Eco, un admirador de la figura de Wilkins, al que dedica un ingenioso capítulo ${ }^{21}$. Y el hecho de que el ensayo y la narración se entremezclen en la obra borgiana es también otro punto en común con Eco. Y si considera que un relato que se ramifica en múltiples historias es un laberinto (1983a), también ha de constituir un laberinto el relato que se impregna de contenidos ensayísticos y deviene una novela filosófica.

Umberto Eco es un novelista prestigioso y singular. Con esta valoración no nos referimos tanto a la gran aceptación de su obra como a un factor que quizá ha pasado inadvertido. Se trata de que buena parte de su narrativa aporta un material de gran interés para la historiografía lingüística. En su primera novela, El nombre de la rosa (1980), muestra su querencia por la metafísica policíaca y la indagación teórica: “La novela constituye una historia de conjetura, en estado puro", afirma el autor, "pero también una detección médica, una investigación científica e, incluso, una interrogación metafísica” (1983a: 65). Bajo la trama y los diálogos de los personajes Eco trenza teorías sobre la argumentación, la semiótica y la ética medievales. Y en la siguiente novela, El péndulo de Foucault (1988), la historia opera con aspectos semióticos de juegos de impostura, secretismo y confusiones dramáticas.

Volvamos de nuevo a la conferencia de Eco de 1992 en La Coruña. Pronunció en el preámbulo unas palabras reveladoras a modo de presentación del tema de la lengua perfecta. Era “el sueño de una lengua capaz de hermanar a todos los hombres”, una utopía afín a "la Isla Perdida o a la Tierra Ignota, a un Graal” (Eco 1994b). Los ejemplos que mencionó para comparar un asunto de la historia de la lingüística tenían una intención que trascendía la ocasión y que han motivado dos novelas de Eco. La

\footnotetext{
${ }^{21}$ J. L. Borges, “El idioma analítico de John Wilkins”, Otras inquisiciones, Buenos Aires, Emecé. 1960. Precisamente de esta obra surgió un título de referencia sobre la historia del pensamiento y el lenguaje, Las palabras y las cosas”, de Michel Faucault (1966).
} 
búsqueda del Grial es uno de los frentes narrativos de Baudolino (2000), una novela histórica localizada en un personaje del siglo XII ligado al terruño piamontés de Eco ${ }^{22}$. Por su parte, la búsqueda de la "isla perdida” o la "tierra ignota” es un asunto por el que estaba especialmente interesado en aquellos momentos. Es el núcleo de la novela en la que estaba trabajando y que publicaría en 1994 con el título de La isla del día de antes.

Pues bien, la ponencia de La Coruña fue un adelanto de los asuntos que Eco estaba pergeñando en los manuscritos de su tercera novela y del ensayo sobre la lengua perfecta. La isla del día de antes es una novela también histórica, ambientada en el tiempo de la exploración oceánica del siglo XVII. Su particularidad es que quizá resulte la menos narrativa de la producción de Eco, porque tiene un componente expositivo considerable. En efecto, es una novela de tesis por la profusión de teorías sobre pensamiento y ciencia experimental. Se explican mediante el discurso del narrador y los diálogos. A su modo, es una enciclopedia sobre la revolución científica. Es fácil predecir que entre las referencias aparecen los proyectistas del lenguaje, afectos a instituciones como la Royal Society of London, el Vaticano y las cortes europeas.

La trama es escueta y su nudo se resume en pocas líneas. En el verano de 1643, el joven y noble piamontés Roberto de la Griva arriba como náufrago a un navío desierto, el Daphne. "Soy, creo, a memoria de hombre, el único ser de nuestra especie que ha hecho naufragio en una nave desierta”, dice para sí el protagonista (1994a: 11) ${ }^{23}$. Es el arranque de un argumento barroco. La acción sucede en los mares del Sur, a donde se ha dirigido por encargo del primado Mazarino con la misión de descubrir el Punto Fijo o cambio de día. El azar dispone que el Daphne esté embarrancado frente a la isla del día de antes, la del cambio de día y que el náufrago la contemple sin posibilidad de llegar hasta ella. Al cabo de unos días el protagonista descubre en una cámara secreta al jesuita Caspar Wanderdrossel, un científico apasionado por la experimentación y el conocimiento.

\footnotetext{
22 El fantasioso y pícaro Baudolino se gana el afecto de Federico Barbarroja y le empuja a recuperar el Santo Grial para el Preste Juan. La novela es una celebración del mito y la utopía. Anteriormente Eco ya había tratado de “El milagro de San Baudolino” en el El segundo diario mínimo (1992, capítulo IV, p. 421-434 de la traducción al catalán).

${ }^{23}$ Las citas y referencias de página proceden de la edición de 1997 por Plaza \& Janés, pero puede según el tipo de edición.
} 


\section{El maestro Kircher}

La lectura de la novela sugiere que Eco se ha valido del género narrativo para recopilar amenamente la historia del pensamiento y la ciencia del siglo XVII. En sus páginas se reflejan tanto los modelos racionalistas y empiristas de la filosofía como la inventiva tecnológica y los avances en cartografía. Pero también hay un lugar para la preceptiva literaria y la teoría semiótica. No puede sorprender que algunos de los personajes sean un trasunto de personalidades históricas. Y abundan los párrafos con citas de obras y las referencias a títulos de ciencia.

En una enciclopedia dramatizada del siglo XVII como es La isla del día de antes no podía faltar un capítulo sobre el “Arte de la prudencia” (cap. 11). En él se acredita la influencia de Gracián y, especialmente, de Torquato Acceto, autor de La disimulación honesta (1641), de quien se sigue este pasaje de la novela: "En esta vida, no siempre se debe ser de corazón abierto, y las verdades que más nos importan vienen siempre a medio decir. La disimulación no es engaño. Es industria de no hacer ver las cosas como son” (1994a: 136). La invitación a la disimulación desaconseja la simulación y propone la agudeza como virtud del cortesano, con aforismos cono éstos (1994a: 136). “El hombre prudente, con una frase elegante, se quita de enredo, y sabe usar la lengua con la ligereza de una pluma”. "La mayoría de las cosas se puede pagar con las palabras”.

La modernidad del arte de la elocuencia se expresa en los epigramas precedentes. Recuerdan en especial el Oráculo manual y arte de la prudencia de Graciàn (1647), por el estilo conceptista y la referencia a un mundo de apariencias y también de agilidades retóricas, que “en Italia llamaban spezzata disinvoltura y en España, despejo” (1994a: 186). Vuelve el autor sobre la filosofía política en el capítulo 31, "La idea de un Príncipe Político” y en otro de gracianesco título, “Agudeza y Arte de Ingenio”. Y Eco inserta en la trama disquisiciones sobre la teoría política de Maquiavelo. Y la aparición de Mazarino como personaje evocado sugiere una conexión con la supuesta obra del estadista, Breviario para políticos, que Eco prologó para una edición de $1996 .{ }^{24}$

\footnotetext{
${ }^{24}$ El prologo de Eco se titula“Los signos del poder. El Breviario de los políticos, atribuido al poderoso regente de Francia en la niñez de Luis XIV. el cardenal Mazarino, es un descarnado y cínico manual de comportamiento para conseguir el poder y conservarlo. La finalidad de la obra es la sátira de un mundo en
} 
Además de la retórica, hay en la novela contribuciones sobre historia política, cartografía, tecnología y, por supuesto, la semiótica del barroco. De esta última trata en el capítulo “Declaración magistral sobe los emblemas” y desarrolla la teoría de la “empresa” o símbolo:: “Cualquier buena Empresa debía ser metafórica, poética, compuesta sí por un alma toda por descubrir pero, en primer lugar, por un cuerpo sensible que remitiera a un objeto del mundo, y debía ser noble, admirable, nueva pero conocible, aparente pero actuosa, singular, proporcionada al espacio, aguda y breve, equívoca y escueta, popularmente enigmática, apropiada, ingeniosa, única y heroica” (cap. 26, p. 397). ${ }^{25}$

La caracterización de los personajes es otro rasgo distintivo de la novela de Eco. Recrea el lenguaje de la época y usa el colorista idiolecto de Capar, el jesuita alemán, como una paleta para pintar su espíritu vivaz. Caspar ejerce de maestro de astronomía ante Roberto y diserta sobre el secreto del Punto fijo o del cambio de fecha. "Porque aquí está el meridiano ciento ochenta, que es exactamente el que la tierra en dos separa, y por la otra parte está el primer meridiano. (...) Aquí es media noche, y en aquel primer meridiano es medio día. ¿Verstanden? ¿Tú adivinas agora por qué las Islas de Salomón han sido así llamadas? Salomón dixit corta niño en dos, Salomón dixit corta Tierra en dos” (p. 293).

El personaje de Caspar es fundamental en la La isla del día de antes. Por ello conviene describirlo para interpretar qué representa. El padre Caspar Wanderdrossel e Societate Iesu es profesor del Colegio Romano, astrónomo y “estudioso de muchas otras disciplinas”. El narrador lo presenta como “teutón que vivía en Roma hablando con los

el que las virtudes al uso de los políticos dan paso a otras nuevas, en las que la consecución de los objetivos personales eclipsa cualquier consideración de orden moral.

${ }^{25}$ El afán didáctico de Eco se manifiesta en las enumeraciones. He aquí la lista sobre las modalidades de símbolo. "La gente de aquella edad conceptuaba indispensable traducir el mundo entero en una selva de Símbolos, Señas, Juegos Ecuestres, Máscaras, Pinturas, Armas Gentilescas, Trofeos, Insignias de Honor, Figuras Ingeniosas, Reversos esculpidos en las monedas, Fábulas, Alegorías, Apólogos, Epigramas, Sentencias, Shommas, Proverbios, Téseras, Epístolas Lacónicas, Epitafios, Parerga, Inscripciones Lapidarias, Escudos, Glifos, Clípeos y, si me lo permitís, aquí me detengo yo; pero no se detienen ellos.” (cap. 26, p 397) 
hermanos de cien países, pero de la lengua vulgar no tenía mucha práctica”, de ahí que se exprese de una forma tan peculiar, con el ejemplo que aporta el narrador sobre su habla: "Et hete aquí por qué aquella barca por los marineros abandonada nosotros hora non vemos, aunque todavía allá atrás está, ¡heu me miserum!” (p. 285).

Tras esta caracterización se halla el prototipo del científico de la época, con un espíritu que armoniza experimentación y especulación teórica. Es más, el científico del barroco es el trasunto de un jesuita que publicó múltiples obras y ejerció una gran actividad en Roma con la creación del germen de los museos vaticanos. Se trata de un autor que aparece reiteradamente en La búsqueda de la lengua perfecta en la cultura europea. Es Athanasius Kircher (Geisa, Alemania, 1602 - Roma, 1680), el autor de El laberinto del Mundo, Gran Arte de la Luz y de la Sombra y Telluris Theoria Sacra. Estos son también los títulos de los capítulos 5, 6 y 21 de La isla del día de antes. No puede sorprender la afinidad de Eco con Kicher por su estudio de la historia de los laberintos.

Las proezas de Kircher, que oscilan entre la anticipación científica y la caprichosa imaginación, incluyen la creación de una gramática visual para el aprendizaje de idiomas, la invención de una linterna mágica y de un artilugio de espionaje auditivo, el estudio de la arqueología romana y egipcia, la teorización sobre la geología, el desciframiento fantasioso de jeroglíficos y escritura china, el diseño de un órgano musical de tipo automático... En definitiva, un autor desmesurado por la genialidad de sus investigaciones y la irregularidad de sus resultados. Kircher condensa la figura del sabio que aspira a abarcar el saber universal y que aplica con perspicacia los recursos visuales de la ilustración gráfica.

Kircher participa también del sueño de la lengua perfecta. Su proyecto es erróneo, pero en él aprecia Eco la "felix culpa”, el error afortunado que desencadena, ya en otra época, nuevas investigaciones y provechosos resultados. "Cada uno de los proyectos debe, por tanto, ser visto como un ejemplo de felix culpa: muchas de las teorías que hoy ponemos en práctica y las prácticas que conocemos, han nacido de la quéte de una lengua perfecta” (Eco 1994b:80). 
10. Decálogo del historiador de Babel

El naufragio de Roberto de la Grive, frente a la isla perdida, narra un episodio fallido de la exploración marina. La ficción permite al autor recrear un escenario mítico, en el Pacífico Sur, y abrir una cátedra en la que exponer ideas filosóficas y experimentales de la época. Y su estrategia narrativa es la dilación o demoratio, un rasgo distintivo de su estilo neobarroco al que tan afecto se siente (Eco 1994: 57-82). ${ }^{26}$ A este ritmo pausado, más argumentativo que argumental, aplica una estética postmoderna, con la interferencia de historias y también de mundos. La narración de $L a$ isla es como un laberinto porque se trata de escritura experimental. En el relato se alternan historias, se mezcla realidad y delirio, se equipara la creación del narrador y la creación autónoma de los personajes. Es una obra abierta, una propuesta imaginativa que da juego a la interpretación del lector.

Eco aplica en su relato lo que, como teórico, predicó de Borges, que "superó la intertextualidad para anticipar la era de la hipertextualidad en la que no sólo un libro habla del otro, sino que desde el interior de un libro se puede penetrar en otro" (Eco 2002: 126). Y también postula una dimensión teorética para el narrador. Como señala en Apostillas a El nombre de la rosa, se considera un novelista con una función añadida de historiador: "Una novela histórica no sólo debe localizar en el pasado las causas de lo que sucedió después, sino también delinear el proceso por el que esas causas se encaminaron lentamente hacia la producción de sus efectos” (1983a: 92).

Sin duda, la narración puede ser modelo de conocimiento historiográfico. Y las ficciones de Eco -al igual que las de Borges o Joyce influenciaron en Eco (2002: 145)muestran cómo se puede hacer afirmaciones filosóficas al narrar una parábola de la exploración marítima. La historia de la lingüística es una empresa de exploraciones que tiene una afinidad con la biblioteca de Babel y la parábola de Borges, como intento de abarcar el esquema del universo histórico. Según el modelo del árbol, se intenta llegar a

\footnotetext{
${ }^{26}$ La preferencia por los efectos de la dilación se refleja en un acontecimiento cultural dirigido por Eco para el museo del Louvre en 2009, El vértigo de las listas. Véase en la publicación homónima (Eco 2009), el capítulo sobre la “Retórica de la enumeración” ( p. 133-151). El vértigo de las listas se convierte en un viaje hacia el infinito mediante los recursos de la amplificación y la dilación.
} 
un orden provisional y parcial con el análisis de los elementos. En cambio, según el modelo borgiano o del laberinto, la elección es la opuesta: la recomposición de las ideas en una inacabable combinación. En consecuencia, Eco concibe "el universo milenario del saber como danza de átomos, entrecruzándose de citas, aglutinarse de ideas, para producir no sólo todo lo que ha sido y es, sino también lo que será o podría ser, tal y como es tarea y posibilidad de los bibliotecarios de Babel” (2002: 126). Hasta el momento, la historia la lingüística corrobora este modelo, puesto que se han sucedido en ella tres fases, que han supuesto una revisión radical de sus presupuestos, tópicos y preguntas.

El modelo de la historiografía como laberinto, como relato del trayecto de su explorador, puede expresarse con la imagen del bosque. "Un bosque es, para usar una metáfora de Borges, un jardín cuyas sendas se bifurcan” argumenta Eco (1994: 14), pues por sendas o en la espesura cada cual traza su propio recorrido. Como el lector ante un texto narrativo, el historiador se ve obligado a efectuar elecciones continuamente. Y su discurso es precisamente la memoria de su recorrido, de los criterios y de los hallazgos. Se trata del historiador de Babel, cuyas cualidades pueden estipularse en un decálogo de principios, que proponemos a continuación. Es la consecuencia de nuestra interpretación de la historiografía reciente. Y tiene la influencia formal de Eco, ya que imita el estilo del decálogo que Eco compuso para la biblioteca de Babel. ${ }^{27}$

\footnotetext{
${ }^{27}$ El decálogo imita otro de Eco sobre la "Biblioteca de Babel” (1983b). Por la admiración que Eco ha manifestado hacia la imagen borgiana de la biblioteca de Babel, aceptó la invitación de participar en un encuentro de bibliotecarios. Para la ocasión redactó un decálogo irónico sobre la gestión de una biblioteca, que obtuvo una excelente acogida (Eco 1983c). Una variante con 18 preceptos se recoge en El segundo diario mínimo (1992: 105-7).
} 


\section{El historiador de Babel}

1. El historiador de Babel se ocupa de lingüística, filosofía, literatura e historia del arte, entre otras disciplinas.

2. El historiador de Babel frecuenta los géneros del ensayo historiográfico y de la narración.

1. Concibe la narración de ficción como una fuente de conocimiento.

4. Concibe la historia como una dimensión de obras abiertas y como un proceso interpretativo.

5. No es un especialista de la historiografía, sino que la cultiva como extensión de otras investigaciones.

6. Aplica los estudios históricos a diversos ámbitos de la lingüística, sobre los que proyecta una perspectiva histórica.

7. Desarrolla la historia de la lingüística como exploración científica y no como justificación de su modelo teórico.

8. Sus estudios tratan de cuestiones que afectan los paradigmas epistemológico, gramatical, discursivo y metodológico de la historiografía.

9. Está interesado no sólo en publicar qué descubre, sino también en explicar cómo investiga y cómo escribe.

10. Comunica con entusiasmo su labor y contagia el interés por la historiografía, tal como lo haría una celebridad social con dotes de orador.

Norma áurea: Es original y refunda la historiografía, porque escribe tanto para los lectores contemporáneos como para los futuros. 


\section{La historiografía y el lector}

La perspectiva del tiempo permitirá decir si los rasgos del historiador de Babel son consistentes. También dará lugar a considerar si constituyen las características de una nueva etapa de la historia de la lingüística. Nuestra pregunta inicial sobre cuál es el historiador perfecto nos ha conducido a este punto. Era una pregunta delicada porque podía implicar erróneamente que el prestigio y la fortuna de una disciplina están en las manos de una figura. Sea ésta un genio o bien una celebridad de su tiempo, no parece razonable personalizar hasta ese punto. El destino de la historiografía no es adoptar una voz como guía ni modelo, sino reconocer las múltiples voces y la diversidad de recorridos con que se construye la historia.

De los numerosos actores que han aportado su trabajo hemos apreciado las figuras que representan mejor cada una de estas etapas. En la fundacional, figura el indiscutible nombre de V. Thomsen. En la estructuralista o axiomática, de tan nutrido número de autores, R. H. Robins merece mucho reconocimiento. En la tercera o hermenéutica hemos considerado el papel de un lingüista tan relevante como Umberto Eco. No obstante, puede parecer paradójica la elección del semiótico porque su prestigio se asienta en su obra como teórico y analista de la comunicación social.

Más allá de este perfil, el rasgo que mejor definiría la actividad de Eco es la atención permanente a la historia. Sus excelentes aproximaciones a la Edad Media y a otros períodos de la historia son excelentes iluminaciones del presente. Difícilmente haya una obra suya que escape al designio historiográfico ${ }^{28}$. Para ilustrar ese programa interpretativo, que articula conocimiento histórico y actualidad, basta consultar el escueto y brillante artículo “La Nueva Edad Media ha comenzado ya” (1973: 9-34) ${ }^{29}$. Y

\footnotetext{
${ }^{28}$ En Apostillas a El nombre de la rosa reconoce su permanente visión histórica de la actualidad. “Así, el Medievo siguió siendo, si no mi oficio, mi afición, y mi tentación permanente, y lo veo por doquier, en trasparencia en las cosas de que me ocupo, que no parecen medievales pero lo son” (1983a:: 25).

${ }^{29}$ El artículo, originalmente publicado en una obra en colaboración con F. Colombo, F. Alberoni y G. Sacco, también aparece en una recopilación propia (Eco 1983: 65-85), con el título "Hacia una nueva Edad Media”.
} 
un valor especial acredita su obra autobiográfica, construida con artículos publicados en la prensa cultural, en los que relaciona vivencias y reflexiones. ${ }^{30}$

Pero si el problema de la biblioteca de Babel es equiparable al de la historiografía lingüística, según Eco el factor determinante no es el historiador ni el modelo que se aplique. "A estas alturas, el problema de si la Biblioteca es infinita o de indefinida amplitud y si finito o ilimitado y periódico es el número de los libros que la habitan, se vuelve secundario.” El verdadero factor es un agente, porque “el verdadero héroe de la Biblioteca de Babel no es la Biblioteca misma, sino su Lector, nuevo Don Quijote, dinámico, aventurero, incansablemente inventivo, alquímicamente combinatorio, capaz de dominar los molinos de vientos que giran al infinito.” (Eco 2002: 126).

En numerosos pasajes de su obra, Eco se incorpora como personaje (1992: 125, 428). Y se ofrece al lector para que extraiga sus propias interpretaciones, como elemento de una obra abierta que se presenta tan ambiguamente como la vida misma. "Somos proclives a mezclar ficción y realidad, a leer la realidad como si fuera ficción y la ficción como si

\footnotetext{
${ }^{30}$ Los escritos están recopilados, por ejemplo, en los volúmenes del Diario mínimo (1963) y El segundo diario mínimo (1992). Estas muestras son el indicio de que la atención permanente a la historia de Eco alcanza una envergadura extraordinaria, puesto que ha firmado una producción ingente de títulos. Añádase los discursos de aceptación de más de treinta investiduras como Doctor Honoris Causa -en la Universidad de Sevilla, en 2009, uno de los más recientes- o el del Premio Príncipe de Asturias en comunicación y humanidades de 2000, entre otros. Uno de los últimos y más originales, el Premio del Reino de Redonda (2008), le convirtió en “Duque de la isla del día de antes” por sus méritos como novelista e historiador. Se le concedió “por la increíble agudeza de sus ensayos y la enorme variedad de sus intereses”. Este reconocimiento, en el que intervino el novelista Javier Marías, era también “por su casi inabarcable erudición y su curiosidad infatigable; y por su capacidad de renovación de los géneros novelísticos clásicos a los que ha dado impulso, originalidad y nueva y larguísima vida, de la novela histórica a la detectivesca, de la de intriga a la fantástica, y aún a la científica”.

También mereció la singular distinción de ser el tema del Congreso de Lovaina de 1999, “Eco in fabula”, donde intervino como un maestro ajedrecista ante una partida múltiple con expertos. El Congreso "Eco in fabula” llevaba el subtítulo “Umberto Eco en la ciencias humanas” y se celebró entre el 24 y el 27 de febrero de 1999. Las actas (Musarra 2002) recogen las ponencias, agrupadas en cinco secciones, y las respuestas a cada sección por Eco. En la sección sobre historiografía lingüística, "La búsqueda de la lengua perfecta” (p. 137-183), intervinieron Herman Parret, Pierre Swiggers, David Cram y Jaap Maat, quienes trataron de las lenguas artificiales.
} 
fuera realidad”, afirmaba en el ciclo de conferencias en la Universidad de Harvard (1994: 132), inmediatas a su visita a La Coruña. En una de ellas hizo un emotivo relato de su viaje a La Coruña con motivo del V Congreso de la Sociedad Española de Semiótica. Cuenta con entusiasmo que le invitaron a visitar el Museo de la Ciencia y de la Técnica de la ciudad y el director le anunció que le tenían reservada una sorpresa en el planetario. La oscuridad y la melodía de una canción de cuna de Falla le hicieron sentir el recogimiento y la intimidad de contemplar la bóveda de estrellas.

Continúa su relato diciendo que vio girar sobre su cabeza, como le indicaron, exactamente el mismo cielo que se veía sobre la ciudad de Alessandria en la noche de su nacimiento, entre el 5 y el 6 de enero de 1932. Vivió una experiencia hiperreal esa primera noche de su vida que, por supuesto, no había visto al nacer. “Tuve la impresión de ser el único hombre sobre la faz de la tierra (desde el principio de los tiempos) que se estuviera reuniendo con su propio principio. Era tan feliz que experimenté la sensación (casi el deseo) de que podía, de que habría debido morir en ese momento.” La confidencia de Eco llega a su momento más intenso con una declaración muy emotiva. "Habría podido morir porque ya había vivido la más hermosa de las historias que hubiera leído jamás en mi vida” porque “era un relato cuyos protagonistas eran las estrellas y yo”. Y a continuación aporta un análisis semiótico del relato. "Era ficción, porque la historia había sido reinventada por el director del planetario, era Historia, porque contaba qué había sucedido en el cosmos en un momento del pasado, era vida real porque yo era verdadero y no el personaje de una novela. Era, por un momento el Lector Modelo del Libro de Libros.” (Eco 1994: 153-4)

En efecto, somos proclives a mezclar ficción y realidad, de cuya combinación surgen nuevas realidades. La suma de todas ellas forma la biblioteca de Babel, el libro de los libros. Y en su centro se sitúa el lector. Para el lector, el laberinto que se abre en la biblioteca es la una "promesa de narratividad y, por tanto, de realidad" (Eco 1992: 428). La lectura es también para la historiografía la promesa de realidad. Y la historia de la lingüística puede adoptar como principio la máxima del novelista Italo Calvino, que concibe los libros como laberintos. El autor de Si una noche de invierno un viajero, al que admira Eco, dijo que "leer es ir al encuentro de algo que está a punto de ser y aún nadie sabe que será”. Y este puede ser el principio de la historia de la lingüística perfecta. 
La lección de Eco se resume en la máxima de que la novela constituye una "historia de conjetura en estado puro”, un género para la investigación científica (1983a: 65). Aspirar a la perfección comporta concebir una historiografía acorde con la biblioteca de Babel. En la estela de la novela La isla del día de antes y el ensayo La búsqueda de la lengua perfecta, el programa historiográfico puede acoger libromundos, es decir, libros que ponen en cuestión los géneros, libros que abarcan épocas o grandes períodos. Los libromundos son, en definitiva, obras que cambian las reglas de la historia.

La literatura posmoderna se centra en el problema de los códigos y su desarticulación, por encima del relato de vidas y peripecias de los personajes. Así sucede en La isla del día de antes, la novela científica y de experimentación de Eco. Pues bien, tal como hace la literatura contemporánea, también la historiografía puede indagar sobre cuál es el código que construye la historia del pensamiento y la cultura. Demuestra su progreso así, al investigar a cerca de los mecanismos de esas construcciones y al ensayar construcciones distintas. Finalmente corresponde a los historiadores de la lingüística remover un obstáculo que dificulta su evolución. El obstáculo consiste en que este modelo es tan diferente que puede permanecer incomprendido o, incluso, inadvertido.

Referencias bibliográficas

Aarsleff, Hans (1970): "The History of Linguistics and Professor Chomsky", en Language, 46 (1970), pp. 570-585.

Auroux, Sylvain, ed. (1989-2000): Histoire des idées linguistiques, Liège, Margada Editeur, 3 vols. Vol I, La naissance des métalangages en Orient et en Occident.

Barthes, Roland (1967): "El discurso de la historia”, en Barthes, El susurro del lenguaje, Barcelona, Paidós, 1987; pág. 163-177. 
Bonito Oliva, Achille ed. (1981): Luoghi del silenzio imparziale. Labiritno contemporaneo, Milano, Feltrinelli,

Cerny, Jirí (1996): Historia de la lingüística, Cáceres, Universidad de Extremadura, 1998.

Chomsky, Noam (1966): Lingüística cartesiana, Madrid, Gredos, 1972.

Coseriu, Eugenio (1977): Tradición y novedad en la ciencia del lenguaje: estudios de historia de la lingüística, Madrid: Gredos, 1977.

Eco, Umberto (1963): Diario mínimo, Barcelona, Península, 1964, 1988.

—. (1965): Apocalípticos e integrados. Barcelona, Lumen, 1968.

—. (1975): Tratado de Semiótica General, Barcelona, Lumen, 1977..

—. (1980): El nombre de la rosa, Barcelona, Lumen, 2000.

—. (1981): "Dall'albero al labirinto", en Achille Bonito Oliva, ed., Luoghi del silenzio imparziale. Labirinto contemporaneo, Milano, Feltrinelli, 1981, p. 39-50.

—. (1983a): Apostillas a El nombre de la rosa, Barcelona, Lumen, 2000.

—. (1983b): La biblioteca de Babel. Decàleg, Palma de Mallorca, 1986 (en L'Espresso, 13 de noviembre de 1983).

—. (1983c): “·El antiporfirio”, en Gianni Vattimo, Pier Aldo Rovatti, eds.(1983), El pensamiento débil, Madrid, Cátedra, 1988, p- 76-114.

—. (1984a): Semiotics and the philosophy of language, Macmillan Press, Edición en catalán, Semiòtica i filosofia del llenguatge, Barcelona, Laia, 1988.

—. (1984b), “Prólogo” a P. Santarcangeli, El libro de los laberintos, 1984, p. 13-17.

—. (1990): Los límites de la interpretación, Barcelona, Lumen, 1992.

—. (1992): El segon diari mínim, Barcelona, Destino, 1994.

- (1993): La búsqueda de la lengua perfecta en la cultura europea, Barcelona, Crítica, 1994. 
Eco, Umberto. (1994a): La isla del día de antes, traducción de Helena Lozano Miralles, Barcelona, Plaza \& Janés, 1997.

—. (1994b): "La búsqueda de la lengua perfecta en la cultura europea”, en J. M. Paz Gago, edit., Semiótica y modernidad, La Coruña, Universidad de La Coruña, 1994, p. 79-94.

-. (1994c): Seis paseos por los bosques narrativos- Harvard University, Norton Lectures 1992-1993, Barcelona, Lumen, 1996.

—. (1996): “Los signos del poder”, en Cardenal Mazarino, Breviario para políticos, Barcelona, De Bolsillo, 2007.

—. (1996): Cinco escritos morales, Barcelona, Lumen, 1998.

—. (1997): Kant y el ornitorrinco, Barcelona, Lumen, 1999.

—. (1999): “Tiempos”, en Kristen Lippincott (1999). P. 10-15.

—. (2000): Baudolino, Barcelona, Lumen, 2001.

—. (2002): Sobre literatura, Barcelona, RqueR editorial, 2002.

—. (2004): La misteriosa llama de la reina Eloana, Barcelona, Lumen, 2005.

—. (2007): Dall'albero al labirinto. Studi storici sul segno e l’interpretazione, Milán, Bompiani.

—. (2009): “Discurso de investidura”, en Universidad de Sevilla (2009): Acto de investidura como Doctor Honoris Causa de la Universidad de Sevilla del prodessor Dr- Umberto Eco, Sevilla, Universidad de Sevilla; p. 51-82.

—. (2009): El vértigo de las listas, Barcelona, Random House-Mondadori y Lumen.

Eco, Umberto et alii (1987): Le ragioni della retorica, Modena, Mucchi Editore.’Il messaggio persuasivo”, p. 11-27, Actas del Congreso "Retorica, verita, opinione, persuasione”, Cattolica, 22 de febrero-20 de abril de 1985, editadas por Gabriella Fenocchio.

Eco, Umberto; Colombo, Furio; Alberoni, Francesco; Sacco, Giuseppe (1973) La nueva Edad Media, Madrid, Alianza Editorial, 1973, 1984. 
Eco, Umberto; Carrière, J. Claude (2009): Nadie acabará con los libros, Barcelona, Lumen, 2010.

Espelt, Ramon (2008): Laberints: llocs, textos, imatges, films, Barcelona, Laertes.

Harris, Roy; Taylor, Talbot J. (1989): Landmarks in Linguistic Thought: The Western Tradition from Socrates to Saussure. Londres, Routledge.

Ivic, Milka (1963): Trends in Linguistics, Londres, Janua Linguarum, 1965.

Joseph, John E.; Love, Nigel; Taylor, Talbot J (2001): Landmarks in Linguistic Thought II: The Western Tradition in the Twentieth Century. Londres, Routledge.

Koerner, Konrad; Asher, R. E., eds. (1995): Concise History of the Language Sciences, Oxford, Pergamon.

Laborda Gil, Xavier (1978): La gramática de Port-Royal: fuentes, contenido e interpretación, tesis de licenciatura, Barcelona, Universidad de Barcelona, 1978.

—. (2002): “Historiografía Lingüística: Veinte principios del programa hermenéutico”, Revista de Investigación lingüística, RIL., No 1, Vol. V, 2002, p. 179-207, Universidad de Murcia.

—. (2005): “Historiografía Lingüística y visibilidad de la Retórica”, Revista de Investigación lingüística, RIL., No 8, Vol. VIII, 2005, p. 85-130.

—. (2009): “Fundación de la Historia de la Lingüística por Thomsen en 1902”, Tonos Digital, 18 (XII-2009).

Law, Vivien (2003): The History of Linguistics in Europe from Plato to 1600, Cambridge, Cambridge University Press.

Lepschy, Giulio, ed. (1992): History of linguistics. Nineteenth-century linguistics, Londres, Longman.

Leroy, Maurice (1964): Las grandes corrientes de la lingüística, México y Madrid, Fondo de Cultura Económica, 1969.

Lippincott, Kristen (1999): El tiempo a través del tiempo, Barcelona, GrijalboMondadori, 2000.

Lozano, Jorge (1987): El discurso histórico, Madrid, Alianza Universidad. 
Malmberg, Bertil (1991): Histoire de la linguistique: de Sumer à Saussure, Paris, PUF. Manrique Sabogal, Winston (2011): “Encuentro Umberto Eco - Javier Marías. Diálogo politeísta”, El País, Babelia, 22-1-2011.

Mounin, Georges (1967): Historia de la lingüística. Desde los orígenes al siglo XX, Madrid, Gredos, 1968.

Musarra, Franco et alii, ed. (2002): Eco in fabula. Umberto Eco in the Humanities, Firenze, Franco Cesari Editore.

Parret, Herman, ed. (1976): History of linguistic thought and contemporary linguistics, Berlín, W. de Gruyter.

Paz Gago, José María; Fernández Roca, José Angel; Gómez Blanco, Carlos Juan, edit. (1994): Semiótica y modernidad : actas del V Congreso Internacional de la Asociación Española de Semiótica, La Coruña, 3-5 de diciembre de 1992, La Coruña, Universidad de La Coruña, 2 volúmenes.

Robins, Robert H. (1951): Ancient \& mediaeval grammatical theory in Europe, with particular reference to modern linguistic doctrine, Port Washington (N.Y.), Kennikat Press.

—. (1967): Breve historia de la lingüística, Madrid, Paraninfo, 1974.

Santarcangeli, Paolo (1967, 1984): El libro de los laberintos, Madrid, Edicione Siruela, 1997.

Sebeok, Thomas E. (edit.) (1975): "Historiography of Linguistics", volumen 13 de Current Trends in Linguistics, The Hague, Mouton, 1968-1975.

Swiggers, Pierre (1997): Histoire de la pensée linguistique. Analyse du langage et reflexion linguaistique dans la culture occidentale, de l'Antiquité au XIXe. siècle, Paris, PUF.

Tagliavini, Carlo (1969): Panorama di Storia della linguistica, Bologna, Pàtron.

Thomsen, Wilhelm (1902): Sprogvidenskabens historie; en kortfattet fremstilling [Historia de la Lingüística; una exposición concisa], Universidad de Copenhaguen (G.E.C. Gadd). Traducción al castellano de Javier de EchaveSustaeta: Historia de la Lingüística, Madrid, Labor, 1945. 
Tuson, Jesús (1982): Aproximación a la historia de la lingüística, Barcelona, Teide.

Universidad de Sevilla (2009): Acto de investidura como Doctor Honoris Causa de la Universidad de Sevilla del prodessor Dr- Umberto Eco, Sevilla, Universidad de Sevilla.

Vázquez Medel, Manuel Ángel (2009): “Laudatio”, en Universidad de Sevilla (2009): Acto de investidura como Doctor Honoris Causa de la Universidad de Sevilla del prodessor Dr- Umberto Eco, Sevilla, Universidad de Sevilla; p. 9-50.

Verdú, Vicente (2010): “Entrevista a Umberto Eco”, El País.com, 25-04-2010.

Recibido: 3 marzo 2011

Aceptado: 16 junio 2011

Revisado: 19 junio 2011

Publicado: 23 junio 2011

Actualizado: 25 junio 2011 